\title{
Análise das Políticas Públicas Voltadas para Ciência, Tecnologia e Inovação no Brasil e em Minas Gerais
}

\section{Analysis of Public Policies for Science, Technology and Innovation in Brazil and Minas Gerais}

\author{
Mirella de Barros Dilascio Mestranda em Administração Pública e em Propriedade Intelectual e Transferência de \\ https://orcid.org/0000-0002-4239-9609 Tecnologia.Universidade Federal de São João del-Rei (UFSJ) - Brasil. mirella@ufsj.edu.br \\ Daniela Martins Diniz Doutora em Administração. Universidade Federal de São João del-Rei (UFSJ) - Brasil. \\ https://orcid.org/0000-0001-8535-8703 danidiniz@ufsj.edu.br \\ Fabrício Molica de Mendonça Doutor em Engenharia da Produção. Universidade Federal de São João del-Rei (UFSJ) - Brasil. \\ https://orcid.org/0000-0001-8909-6843 fabriciomolica@ufs..edu.br \\ Vânia Aparecida Rezende Doutora em Administração. Universidade Federal de São João del-Rei (UFSJ) - Brasil. \\ https://orcid.org/0000-0002-9879-4552 vaniarezende@ufsj.edu.br \\ Caroline Miriã Fontes Martins Doutora em Administração. Universidade Federal de São João del-Rei (UFSJ) - Brasil. \\ https://orcid.org/0000-0003-0697-7499 \\ carolfontes@ufsj.edu.br
}

\section{RESUMO}

O objetivo deste estudo foi analisar as políticas públicas nacionais e de Minas Gerais voltadas para Ciência, Tecnologia e Inovação (CT\&l), bem como seus impactos na geração de patentes. Para isso, foi realizada uma pesquisa qualitativa, descritiva e longitudinal, abarcando o período de 2000 a 2018. Os resultados evidenciam que o Brasil necessita melhorar sua posição no ranking do Índice de Inovação Global; os dispêndios nacionais estão aquém da meta prevista na Estratégia Nacional de Ciência e Tecnologia; os dispêndios empresariais representam uma menor fatia dos investimentos realizados; há expressiva participação dos Estados na disponibilização de recursos públicos para CT\&l, embora não ocorra de forma equânime. O estado de Minas Gerais aumentou gradativamente no período analisado seus investimentos na área, se destacando em relação ao demais no que diz respeito aos gastos em P\&D e depósito de patentes junto ao INPI.

Palavras-chave: Brasil; gestão de patentes; Minas Gerais; políticas públicas.

\section{ABSTRACT}

The aim of this study was to analyze national and state of Minas Gerais public policies aimed at Science, Technology and Innovation (CT\&l), as well as their impacts on the generation of patents. For this, a qualitative, descriptive and longitudinal research was carried out, covering the period from 2000 to 2018 . The results show that Brazil needs to improve its position in the ranking of the Global Innovation Index; national expenditures are below the target set in the National Science and Technology Strategy; business expenditures represent a smaller share of investments made; there is an expressive participation of States in the provision of public resources for ST\&l, although it does not occur equally. The state of Minas Gerais gradually increased investment in the area over the period analyzed, standing out in relation to the others with regard to spending on $R \& D$ and filing of patents with the INPI.

Keywords: Brazil; patent management; state of Minas Gerais; public policy. 


\section{INTRODUÇÃO}

As políticas públicas voltadas para inovação decorrem primordialmente das políticas de ciência e tecnologia (CT\&l), as quais se caracterizam por legislações e por ações governamentais que visam à promoção do desenvolvimento econômico no país. Partem do princípio de que o conhecimento tem um papel crucial no progresso econômico e que a inovação é um fenômeno complexo e sistêmico (SALERNO; KUBOTA, 2008,).

Para Schumpeter (1961), a inovação é propulsora do desenvolvimento econômico advinda de um processo dinâmico, conhecido como "destruição criativa", em que as novas tecnologias substituem as antigas. Com a conceituação Schumpeteriana, a inovação passou a ser caracterizada por combinações de conhecimento e competências, que pode gerar novos produtos, novos processos, abertura de novos mercados, trazer novas formas de organização, além de descobrir novos materiais (OCDE, 2006).

Desde o início da década de 60, a Ciência e Tecnologia passaram a ocupar uma posição mais central na vida social e econômica, gerando benefícios à sociedade como um todo. Consequentemente, essas tornaram-se foco nas recentes discussões, propostas de políticas e estratégias para o desenvolvimento por instituições públicas e associações empresariais do país, acarretando uma demanda social por conhecimento, tecnologia e inovação (SALLES-FILHO; BONACELLI, 2005 apud TOLEDO, 2009, p. 110).

No Brasil, a estratégia de geração e incentivo de inovação foi negligenciada em detrimento de políticas direcionadas para estabilização econômica. Somente após a aprovação e reestruturação de um conjunto de instrumentos legais, é que passou a haver um suporte mais efetivo às políticas industriais e de desenvolvimento científico e tecnológico, com intuito de se promover o chamado catching up ou emparelhamento tecnológico no país (REZENDE; CORREA; DANIEL, 2013). Os novos dispositivos trouxeram um novo olhar no que diz respeito à inovação no Brasil, incentivando os Estados brasileiros a criarem suas próprias legislações. Neste contexto, despontam-se as políticas públicas voltadas para CT\&I no Estado de Minas Gerais, a exemplo da Lei Mineira de Inovação.

Diante deste cenário, este artigo tem o objetivo de analisar as políticas públicas nacionais e de Minas Gerais destinadas a CT\&l de modo a identificar seus impactos na geração de patentes no período de 20002018. Mais especificamente, buscou-se identificar: i) a evolução da classificação do Brasil no ranking do Índice de Inovação Global; ii) a evolução dos Dispêndios do Governo Federal em CT\&l; iii) os dispêndios nacionais em pesquisa e desenvolvimento (P\&D), por setor institucional; iv) os dispêndios nacionais em $P \& D$ em relação ao produto interno bruto (PIB); v) a distribuição do percentual dos dispêndios dos governos estaduais em P\&D; vi) o percentual dos dispêndios em CT\&l e P\&D em Minas Gerais em relação às suas receitas correntes totais; bem como os depósitos de patentes em Minas Gerais no período de 2000-2018.

A escolha de Minas Gerais é justificável, pois o Estado concentra a maior parte das universidades federais do país, podendo servir de base para a análise de outras regiões. No que tange à sua relevância, a pesquisa justifica-se, em termos teóricos, no sentido de ampliar os estudos nacionais e contribuir para aprimorar o entendimento acerca das políticas públicas nacionais e no Estado, voltadas para CT\&l.

\section{FUNDAMENTAÇÃO TEÓRICA}

Na fundamentação teórica será retratada a contextualização das políticas públicas, assim como as políticas públicas de inovação, tanto no Brasil, quanto no Estado de Minas Gerais.

\subsection{Contextualização das Políticas Públicas}

A política pública, enquanto área do conhecimento, se iniciou nos EUA com Robert McNamara, após a Guerra Fria, em 1948, com ênfase em um caráter mais acadêmico, ou seja, como uma disciplina com foco nos estudos sobre as ações dos governos. Todavia, foi na Europa que a área de política pública surgiu baseada em teorias explicativas sobre a importância do papel do Estado, nas ações sociais (SOUZA, 2006). Para Brasil e Capella (2016) um período de desenvolvimento teórico marcado centralidade dos debates em torno do processo decisório.

A ideia de política pública é algo complexo, que permite variedade de recortes, pois não há uma teoria completa e definida e nem consenso sobre o tema. Os vários conceitos é que formam o que se traduz como política pública (SOUZA, 2006). A definição mais conhecida é a de Laswell (1936), que entende que as decisões e análises sobre política pública implicam responder questões como: quem ganha o quê, por quê e que 
diferença faz. Para Dye (1972), políticas públicas é o que o governo escolhe fazer ou não fazer. Para Lynn (1980) é um conjunto de ações do governo que produzirá efeitos específicos. Peters (1986), é o somatório das ações governamentais que agem diretamente ou por meio de delegação, influenciando a vida dos cidadãos.

Embora seja polissêmico, Souza (2006) destaca que as políticas públicas possuem uma natureza holística, estruturada de forma multidisciplinar, abrangendo diversas áreas do conhecimento, o que permite que seja estudada sob diversos enfoques. Ademais, a formulação de políticas públicas constitui-se nas intenções governamentais de converterem, por meio de programas e ações, propósitos e plataformas eleitorais, com objetivo de produzir resultados ou mudanças no mundo real, de forma a alcançar o bem-estar da sociedade e o interesse público.

Para Brasil e Capella (2016), mesmo perante esse dissenso, o elemento central é a partir da ideia de que o agente mais importante do processo de produção de políticas públicas é o governo.

\subsection{As Políticas Públicas de Inovação no Brasil}

O campo de políticas públicas no Brasil, segundo Laswell (1951 apud FARAH, 2016), tem sua evolução marcada em uma das vertentes da literatura norte-americana, as policy sciences. Dessa origem surgem interpretações diversas que acabam confluindo na ideia dominante de poder decisório governamental (BRASIL; CAPELLA, 2016). Ollaik e Medeiros (2011) contatam que a história da administração pública brasileira está repleta de reformas na busca de instrumentos para melhorar a gestão governamental e a implementação de políticas públicas.

Para Brasil e Capella (2016) os estudos sobre políticas públicas no Brasil apresentam uma significativa ampliação de seus interesses, sejam eles acadêmicos ou dentro da ótica setorial, com por exemplo saúde, educação, inovação, dentre outras. Segundo Lotta (2019) a incorporação de elementos analíticos por meio de estudos setoriais pode trazer ganhos importantes para as áreas específicas e para a aprendizagem dos processos de implementação. A partir da análise setorial pode-se constatar que o Brasil passou a se preocupar de forma tardia com as políticas públicas voltadas para Inovação, tendo como marco a criação do Conselho Nacional de Pesquisas (CNPq), por meio da Lei no 1.310/1951, como órgão específico para "promover e estimular o desenvolvimento da investigação científica e tecnológica em qualquer domínio do conhecimento". A criação do CNPq significou a incorporação da ciência à área de controle do Estado (KORNIS, 2010).

Segundo Marteleto (2009), a visão da ciência como poder do Estado, fruto de um projeto desenvolvimentista da história da Administração Pública brasileira, teve no período denominado "milagre econômico", um ritmo elevado em crescimento, aumentando sua capacidade de arrecadação, e, consequentemente, expandido os recursos destinados para a pesquisa. O Instituto Nacional de Propriedade Industrial (INPI), autarquia federal, foi criado pela Lei no 5.648, de 11 de dezembro de 1970, com a finalidade executar, no Brasil, as normas que regulam a propriedade industrial. Em 1974, pela Lei no 6.129, o CNPq foi transformado em fundação e recebeu seu nome atual, Conselho Nacional de Desenvolvimento Científico e Tecnológico, mantendo-se, porém, a sigla anterior e passando a ser vinculado ao Ministério do Planejamento Econômico, junto com a recém-criada FINEP - Financiadora de Estudos e Projetos (SCHWARTZMAN, 2005; MARTELETO, 2009).

No início dos anos de 1980, em virtude do agravamento da situação econômica do Brasil, na qual ocorreu uma falência generalizada da administração pública e um descontrole inflacionário, iniciou-se uma crise envolvendo a pesquisa científica e tecnológica do país. Nesta época, criou-se o Ministério da Ciência e Tecnologia (MARTELETO, 2009). A partir dos anos de 1990, houve novo processo de rearticulação do CNPq, incentivando e promovendo pesquisas voltadas para o setor produtivo (KORNIS, 2010),

Outra ação governamental diz respeito à regulamentação dos direitos e obrigações relativos à propriedade industrial postulado na Constituição Federal de 1988. O ordenamento jurídico pátrio passou a conferir ampla proteção ao tema. A Constituição Federal em 1988, em seu artigo 5º inciso XXIX, assim dispôs: "A lei assegurará aos autores de inventos industriais privilégio temporário para sua utilização, bem como proteção às criações industriais, à propriedade das marcas, aos nomes de empresas e a outros signos distintivos, tendo em vista o interesse social e o desenvolvimento tecnológico e econômico do País".

Segundo Dantas et al. (2016), por meio da Lei no 9.279/96 foram disciplinados os direitos e obrigações inerentes à propriedade industrial considerado o desenvolvimento tecnológico e econômico do País, bem como ao interesse social e bem comum. Com essa lei, pretendeu-se assegurar aos autores de inventos industriais privilégios temporários para sua utilização, as quais podem se concretizar pela repressão às falsas indicações geográficas e a concorrência desleal, da concessão de registro de marca, de desenho industrial e de patentes. 
Para Arbix et al. (2017), somente em 1999, a inovação começou a ser colocada no centro das preocupações de governo, por meio da criação dos Fundos Setoriais, coordenados pelo Ministério de Ciência, Tecnologia e Inovação (MCTI) e executados legalmente pela Financiadora de Estudos e Projetos (Finep). Esses fundos tiveram como objetivo a implantação de uma nova política de financiamento no país destinada a projetos de pesquisa, desenvolvimento e inovação inerentes à Ciência e Tecnologia. Tratou-se de um programa integrado, com participação de universidades, centros de pesquisa e do setor privado.

A partir da edição da Lei n 10.973/2004, regulamentada pelo Decreto n 5.563/2005, o Brasil passou a direcionar o processo de inovação, a Lei de Inovação Tecnológica estabelece medidas de incentivo à inovação e à pesquisa científica e tecnológica no ambiente produtivo, com vistas à capacitação tecnológica, ao alcance da autonomia tecnológica e ao desenvolvimento do sistema produtivo nacional e regional do País.

Não obstante as diversas tentativas do Governo em melhorar as políticas públicas alusivas à inovação, algumas falhas permaneceram. Para Rauen (2016), os incentivos propostos na Lei de Inovação Tecnológica, como contrapartidas financeiras à ICT, retribuição pecuniária e pagamento de bolsas aos pesquisadores envolvidos em atividades de inovação, não se concretizaram. A Lei de Inovação Tecnológica não foi suficiente para alterar a dinâmica da pesquisa no Brasil, na qual as instituições acadêmicas mantêm o padrão de suas formas de produzir conhecimento para a produção de artigos científicos, não se preocupando com a transferência de tecnologias (RAUEN, 2016).

Outro diploma legal diz respeito à Lei no 11.196, de 21 de novembro de 2005, conhecida como Lei do Bem, a qual permite a concessão de incentivos fiscais às empresas que realizarem pesquisa e desenvolvimento de inovação tecnológica. Segundo Dehnhardt (2013), por meio desta Lei, começaram a ser concedidos incentivos fiscais às atividades inovativas, uma vez que tal normativo permite que empresas criem projetos e apliquem automaticamente os incentivos de natureza fiscal, sem a necessidade de anuência prévia do MCTI.

Com intuito de definir as iniciativas, ações e programas que possibilitassem tornar mais decisivo o papel da CT\&I no desenvolvimento sustentável do país foi lançado o Plano de Ação de CT\&l para o Desenvolvimento Nacional para o período 2007-2010. Segundo Prete (2018), após esse período, foram lançados o Plano de Ação à Estratégia Nacional de Ciência, Tecnologia e Inovação (ENCTI) 2015-2017 e a Estratégia Nacional em Ciência Tecnologia e Inovação 2016-2019, a qual foi revisada e atualizada passando a abranger o período de 2016-2022. Todavia, essa autora destaca que as normas e as políticas até então criadas se mostraram insuficientes sendo necessária proceder alterações na Lei de Inovação Tecnológica. Por isso, houve a necessidade da aprovação da Emenda Constitucional n 85, de 26 de fevereiro de 2015, de forma a inserir dispositivos na Constituição Federal que permitissem a articulação entre entes públicos e privados, assim como o financiamento e a transferência de recursos públicos a entidades privadas de pesquisa (GARCIA, 2017).

Desta forma, o processo de elaboração da nova lei envolveu diversos atores do Sistema Nacional de Inovação (SNI) e de representantes da comunidade de CT\&l, que discutiram por cinco anos sobre as condições mais favoráveis ao crescimento sustentável do país. Essa discussão resultou, em 2016, com a publicação da Lei n० 13.243, também conhecida como Novo Marco Legal da CT\&l. Essa lei, além de modificar a Lei de Inovação Tecnológica, alterou também outras leis relacionadas ao tema (a exemplo da Lei das Fundações de Apoio, Lei de Licitações, Regime Diferenciado de Contratações Públicas, Lei do Magistério Federal, dentre outras), tudo com intuito de clarear e oferecer segurança jurídica aos atores do sistema de inovação. Tal dispositivo foi regulamentado pelo Decreto no 9.283, de 07 de fevereiro de 2018, com o objetivo estabelecer medidas de incentivo à inovação e à pesquisa científica e tecnológica no ambiente produtivo, com vistas à capacitação tecnológica, ao alcance da autonomia tecnológica e ao desenvolvimento do sistema produtivo nacional e regional.

\subsection{As Políticas Públicas de Inovação em Minas Gerais no Brasil}

O estímulo à inovação a partir da legislação federal acabou por incentivar os estados brasileiros a criarem suas próprias legislações.

No Estado de Minas Gerais não foi diferente. Em 16 de dezembro de 1976, foi criada, em 16 de dezembro de 1976, a então Secretaria de Estado de Ciência e Tecnologia (SECT/MG), hoje denominada de Secretaria de Desenvolvimento Econômico (SEDE), e instituído o FUNCET (Fundo Estadual de Desenvolvimento Científico e Tecnológico).

Não obstante, vinculada à SEDE, surge, em 1985, a Fundação de Amparo à Pesquisa do Estado de Minas Gerais (FAPEMIG), criada por meio da Lei Delegada n¹0, a qual tem como propósito induzir e fomentar a pesquisa e a inovação científica e tecnológica do Estado de Minas Gerais (FAPEMIG, 2020). A Constituição do estado de Minas Gerais, promulgada em 1989 e alterada em 1995, destina à FAPEMIG, em seu artigo 212, o percentual de $1 \%$ (um por cento) da receita orçamentária corrente ordinária do Estado para viabilização de 
projetos definidos pelo Conselho Estadual de Ciência e Tecnologia (Conecit). Esses projetos de acordo com o CONECIT devem ser essenciais ao desenvolvimento científico e tecnológico do Estado, e atender à capacitação técnico-científica das instituições de pesquisa do Estado, em conformidade com os princípios definidos nos Planos Mineiros de Desenvolvimento Integrado (PMDls) e contemplados nos Programas dos Planos Plurianuais de Ação Governamental (PPAGs).

Todavia, Marôcco (2008), destaca que, somente no ano de 2005, é que a FAPEMIG estabeleceu um planejamento de CT\&l a médio e longo prazo. Em consequência, nos anos subsequentes à 2005, ampliou-se os recursos aportados na instituição advindos do Governo Estadual, correspondendo, de fato, ao percentual estabelecido na Constituição Mineira. Tal fato, ratificou a credibilidade da FAPEMIG, tornando-a a segunda maior agência estadual de fomento à pesquisa do país (FAPEMIG, 2014).

Em dezembro de 2006 foi publicado em Minas Gerais o Decreto no 44.418, o qual instituiu o Sistema Mineiro de Inovação (SIMI), cuja finalidade, segundo seu Art. $2^{\circ}$ é "promover convergência de ações governamentais, empresariais, acadêmicas de pesquisa e tecnologia para, de forma cooperada, desenvolver a inovação em Minas Gerais".

Em consonância com a política pública nacional, após quatro anos da edição da Lei de Inovação, Minas Gerais criou sua própria Lei sobre o tema (Lei no 17.348/2008).

No final de 2020, o Governo abriu consulta pública para atualização do Marco Mineiro de Inovação (COTA, 2020).

\section{METODOLOGIA}

Para alcançar o objetivo do estudo, foi realizada uma pesquisa qualitativa de cunho descritivo $e$ analítico, com recorte longitudinal, abarcando o período de 2000 a 2018, estendendo-se a 2020 quando os dados já haviam sido disponibilizados (HAIR-JR et al., 2005). Foi realizada uma revisão narrativa da literatura das informações alusivas às políticas públicas brasileira, assim como das políticas públicas do Estado de Minas Gerais, voltadas para Ciência, Tecnologia e Inovação. As revisões narrativas apresentam uma temática mais ampla, não utilizando critérios explícitos e sistemáticos para a busca e análise crítica da literatura, ficando à subjetividade dos autores a seleção dos estudos e a interpretação das informações (UNESP, 2015). Buscou-se ainda, fazer análise dos indicadores inerentes ao tema, tendo como base os dados disponibilizados pela Organização Mundial de Propriedade Intelectual (OMPI), pela Coordenação-Geral de Gestão Institucional (CGAI) - Departamento de Governança Institucional da Secretaria-Executiva (DGI/SEXEC) - MCTIC e pelo INPI.

O procedimento metodológico foi realizado em três etapas, quais sejam: 1 ) revisão de literatura sobre políticas públicas desenvolvidas no Brasil e em Minas Gerais, com a finalidade de conhecer sua importância para o país. Para tanto, foi realizada uma pesquisa bibliográfica sobre o tema, baseando-se em informações obtidas em dissertações, artigos e livros, no sentido de levantar as contribuições científicas sobre o assunto estudado (CERVO; BERVIAN; SILVA, 2007); 2) coleta de dados em relatórios da OMPI, CGAI/MCTIC, CNPq, INPI e FAPEMIG, com foco nas publicações relacionadas à CT\&I e P\&D. Para isto, realizou-se uma pesquisa documental a partir de informações obtidas nos relatórios citados. De acordo com Martins e Theóphilo (2009), esse tipo de pesquisa tem a finalidade de tratar, compreender e reelaborar as informações obtidas por meio do levantamento do conhecimento científico gerado pelos documentos e provas, de acordo com o propósito de uma nova pesquisa; 3 ) análise dos resultados obtidos, onde identificou-se a evolução da classificação do Brasil no ranking do Índice de Inovação Global, a evolução dos Dispêndios do Governo Federal em C\&T, com ênfoque especial aos dispêndios nacionais em $\mathrm{P} \& \mathrm{D}$ e sua relação com o PIB, a distribuição percentual dos dispêndios dos governos estaduais em P\&D, com enfoque especial para o Estado de Minas Gerais, sendo demonstrada a evolução do número de depósitos de patentes realizados pelo Estado.

\section{DESCRIÇÃO E ANÁLISE DOS RESULTADOS}

De acordo com a OMPI (2020), o Brasil, em 2020, se classificou em $62^{\circ}$ lugar no ranking do Índice de Inovação Global, o qual é composto por 131 países, conforme pode ser observado pelo Gráfico 1. O Brasil obteve apenas 31,94 pontos em uma escala de 0-100. Embora tenha aumentado quatro posições em relação a 2019, essa não é a melhor posição obtida pelo país desde que o ranking foi estabelecido em 2007. 
Verifica-se que o Brasil (Gráfico 1), ao longo dos últimos anos, apresentou uma piora no campo da inovação global. O melhor desempenho do Brasil foi no ano de 2007, quando ocupou a 40ª posição. Após o ano de 2011, o Brasil declinou acentuadamente sua posição no ranking da inovação. Em 2015, o país obteve a sua pior posição, $70^{\circ}$ lugar, o que pode ser atribuído à crise econômica e aos repasses de recursos que influenciaram nos investimentos nas áreas de P\&D.

Gráfico 1 - Evolução da classificação do Brasil no ranking do Índice de Inovação Global

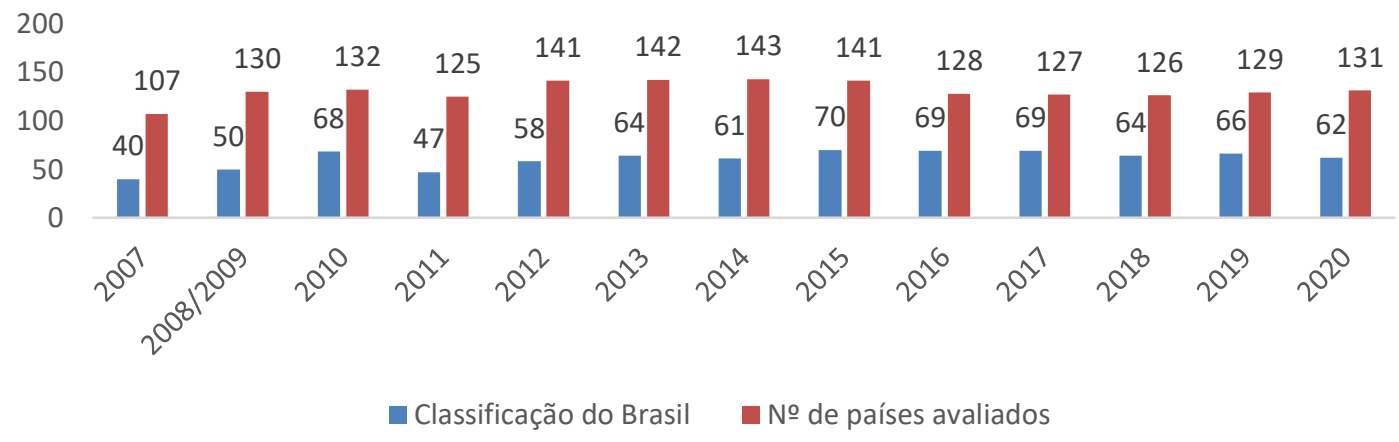

Fonte: Elaborado pelos autores (2020), com base nos dados da Universidade Cornell, INSEAD e OMPI.

Em relação aos demais países da América Latina e Caribe, em 2020 o Brasil aparece na quarta posição atrás apenas do Chile $\left(54^{\circ}\right)$, México $\left(5^{\circ}\right)$ e Costa Rica $\left(56^{\circ}\right)$. No referido ranking, os cinco países mais bem colocados do índice em 2020 são: Suíça, Suécia, Estados Unidos, Reino Unido e Holanda.

Os indicadores do MCTIC (2019) indicam que ampliou os recursos federais destinados à CT\&l no decorrer dos anos. O Gráfico 2 apresenta a evolução do dispêndio nacional em CT\&l de 2000 a 2018. Quanto ao ano de 2018, os dados são preliminares, uma vez que ainda estão em análise pelo MCTIC.

Por meio da análise do Gráfico 2, observa-se que, no período, a cada exercício financeiro, ocorreu um crescimento no montante de recursos destinados à CT\& no país, com exceção dos anos de 2016 e 2017, nos quais o declínio foi de cerca de $6 \%$ se comparado ao exercício anterior. Estas informações tendem a demonstrar a atenção do Governo Federal com as políticas públicas voltadas para CT\&I no país. Todavia, o Manual de Frascati, da Organização para a Cooperação e o Desenvolvimento Econômico (OCDE) considera os dispêndios públicos direcionados para P\&D como uma das principais medidas de esforço de um país para a implantação de sua Política Nacional de Ciência, Tecnologia e Inovação (KOELLER; VIOTTI; RAUEN, 2016).

Gráfico 2- Evolução dos Dispêndios do Governo Federal em CT\&l (em milhões de R\$ correntes)

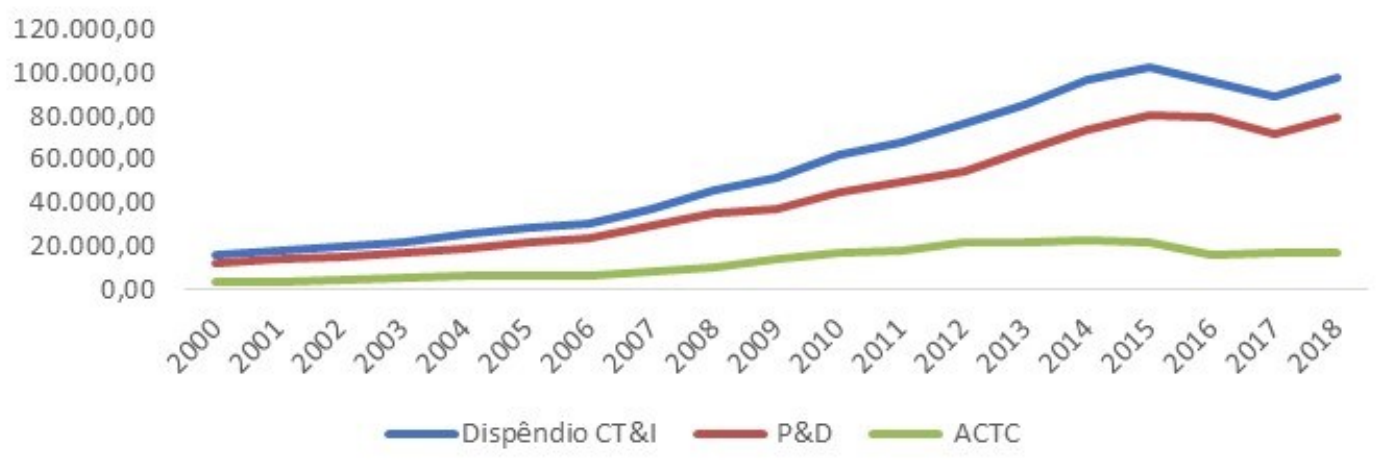

Fonte: Elaborado pelos autores (2020), com base nos dados da CGAI - DGI/SEXEC - MCTIC.

Os gastos com P\&D englobam um conjunto de atividades, envolvendo empresas, universidades e outras instituições científicas com intuito de estimular o desenvolvimento do país. Desta forma, ao analisar detalhadamente os dispêndios em P\&D, Gráfico 3, verifica-se que há um comportamento análogo aos detectados para os dispêndios em CT\&l, isto é, crescimento a cada ano e redução nos anos de 2016 e 2017.

Por meio da análise do Gráfico 3, observa-se que tais declínios atingiram tanto os dispêndios públicos quanto os empresariais. Por meio da análise deste gráfico, constata-se ainda que, no período de 2000 a 2018 , com exceção dos anos de 2002 e 2003, os dispêndios públicos foram maiores que os dispêndios empresariais: enquanto a participação de dispêndios públicos, ficou, em média, de 52,34\% a dos dispêndios empresariais foi, em média, de 47,66\%, retratando a importância das políticas públicas relativas à integração entre governo 
e empresas, a exemplo da Lei do Bem. Porém, há de ressaltar que, em países como Estados Unidos a participação das empresas nos dispêndios para P\&D alcançam 62\%, assim como na China que atingem o patamar de 76\% e no Japão, 78\% (MARQUES, 2016).

Gráfico 3 - Dispêndio nacional em P\&D, por setor institucional, 2000-2018 (em milhões de R\$ correntes)

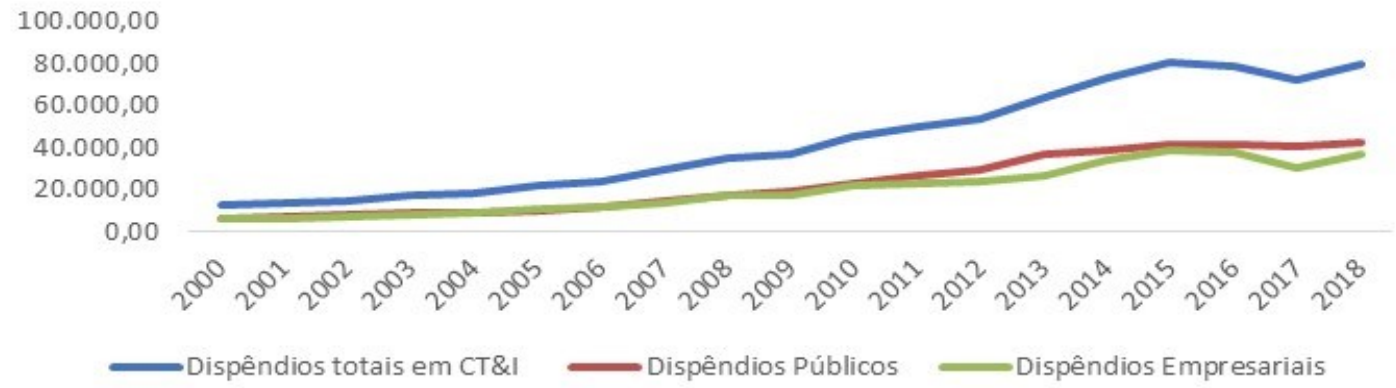

Fonte: Elaborado pelos autores (2020), com base nos dados da CGAI - DGI/SEXEC - MCTIC.

O Gráfico 4 apresenta o dispêndio nacional em P\&D em relação ao Produto Interno Bruto (PIB) no período de 2000 a 2020.

Contudo, os dados apresentados, demonstram que houve declínios quanto à porcentagem dos dispêndios nacionais em relação ao PIB. O cálculo envolve todos os gastos feitos em P\&D pelo setor empresarial e pelo governo, por meio das universidades, instituições de pesquisa e instituições sem fins lucrativos.

Gráfico 4 - Dispêndio nacional em P\&D em relação ao produto interno bruto (PIB), 2000-2018

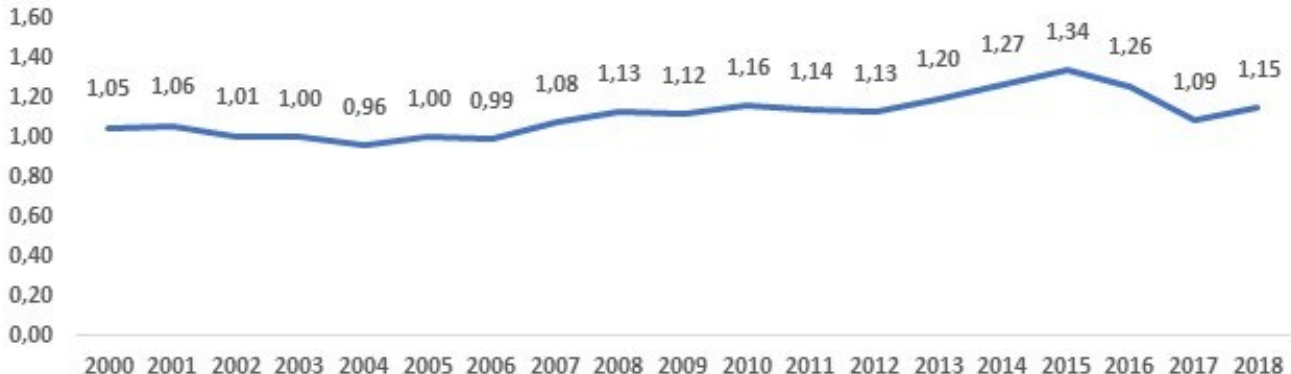

Fonte: Elaborado pelos autores (2020), com base nos dados da CGAI - DGI/SEXEC - MCTIC.

Outra informação relevante, diz respeito ao fato de que a meta prevista na Estratégia Nacional de Ciência e Tecnologia de se investirem 2\% do PIB em P\&D até 2019 não ter sido alcançada, tendo como ápice de investimento o ano de 2015, quando se investiu 1,34\% do PIB em P\&D (Gráfico 4). Mesmo tendo estabelecido a meta de destinar $2 \%$ do PIB para P\&D até 2019, esse percentual é baixo se comparado a países como a Coréia do Sul e Israel que destinam cerca de $4 \%$ de seu PIB para P\&D, conforme dados divulgados pelo Fórum Econômico Mundial.

Outro fator relevante são os dispêndios públicos advindos dos Estados, que representam cerca de $34 \%$ da participação dos recursos. Em 2018, o Estado de São Paulo foi o que mais despendeu recursos para as atividades de $P \& D, 73,60 \%$, seguindo pelo Paraná com $5,86 \%$ e Rio de Janeiro com 5,56\%, conforme consta no Gráfico 5. Mais de $90 \%$ dos recursos advindos da esfera estadual estão concentrados em apenas 8 (oito) Estados da Federação. Os outros 19 (dezenove) Estados, incluindo o Distrito Federal, disponibilizaram, ao todo, 5,68\% dos dispêndios. Se a análise for feita por região, tal disparidade fica mais evidente, uma vez que os Estados do Sudeste foram os que mais despenderam recursos em 2018, na ordem 13.789,30 milhões, o que representa $81,31 \%$ dos recursos estaduais investido em P\&D. Tais assimetrias regionais devem ser combatidas, por meio de políticas públicas, com objetivo de disseminar, de forma equânime, a participação de todos os Estados na produção de P\&D no país. O Estado de Minas é o sexto maior do País em relação aos valores gastos em P\&D. 
Gráfico 5 - Distribuição percentual dos dispêndios dos governos estaduais em P\&D, em 2018

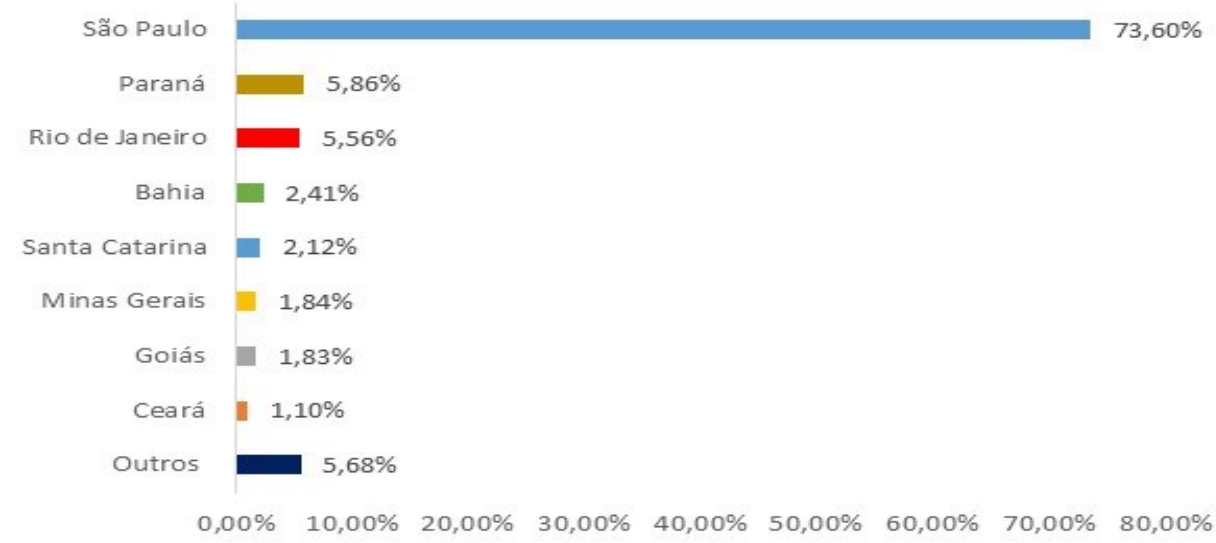

Fonte: Elaborado pelos autores (2020), com base nos dados da CGAI - DGI/SEXEC - MCTIC.

O Gráfico 6, demonstra os dispêndios em CT\&l e P\&D em Minas Gerais entre os anos de 2000 a 2018. No que diz respeito aos valores investido em CT\&l em relação às suas receitas totais, verifica-se, por meio da análise deste gráfico, que nem sempre o Estado cumpriu sua política pública de destinar o percentual de $1 \%$ da receita orçamentária corrente para viabilização de projetos definidos como essenciais ao desenvolvimento científico e tecnológico do Estado, e para a capacitação técnico-científica das instituições de pesquisa. Se analisar somente os recursos disponibilizados pelo Estado para $P \& D$, observa-se que esse percentual está aquém do desejável estabelecido na política pública do Estado (CGAI - DGI/SEXEC - MCTCI, 2019).

Gráfico 6 - Percentual dos dispêndios em CT\&I e P\&D em Minas Gerais em relação às suas receitas correntes totais, 2000-2018 (em milhões de R\$ correntes)

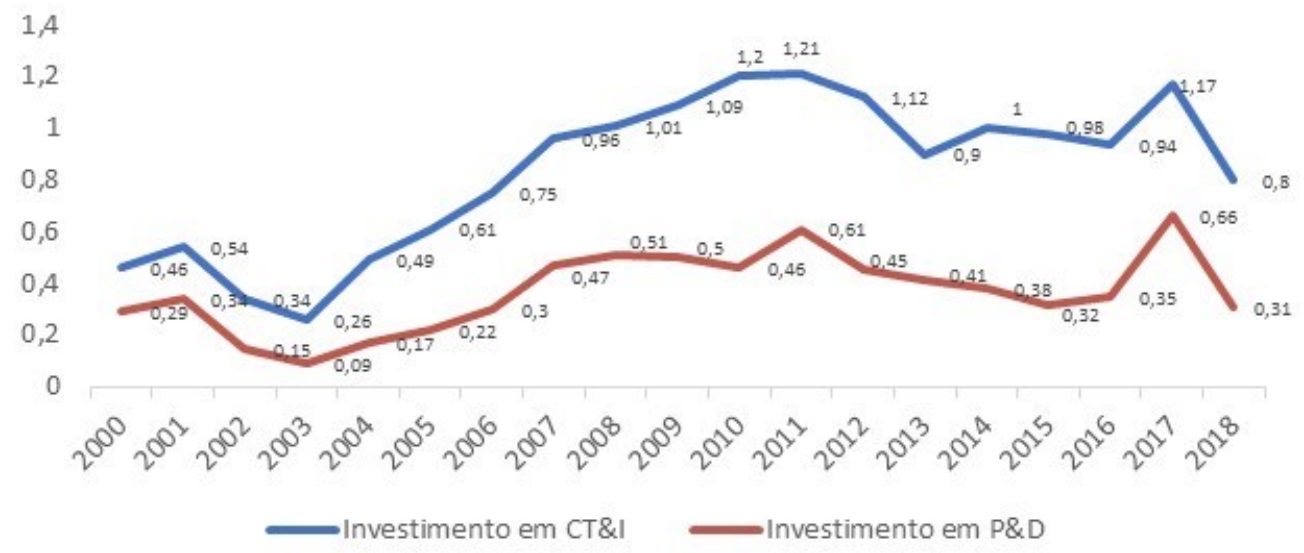

Fonte: Elaborado pelos autores (2020), com base nos dados da CGAI - DGI/SEXEC - MCTIC.

O Gráfico 7 apresenta o quantitativo de depósitos de patentes, sejam de invenção ou modelo de utilidade, depositadas no INPI, no período de 2000 a 2018. 
Gráfico 7 - Depósitos de patentes (invenção + modelo de utilidade), por Estado, no período de 2000-2018

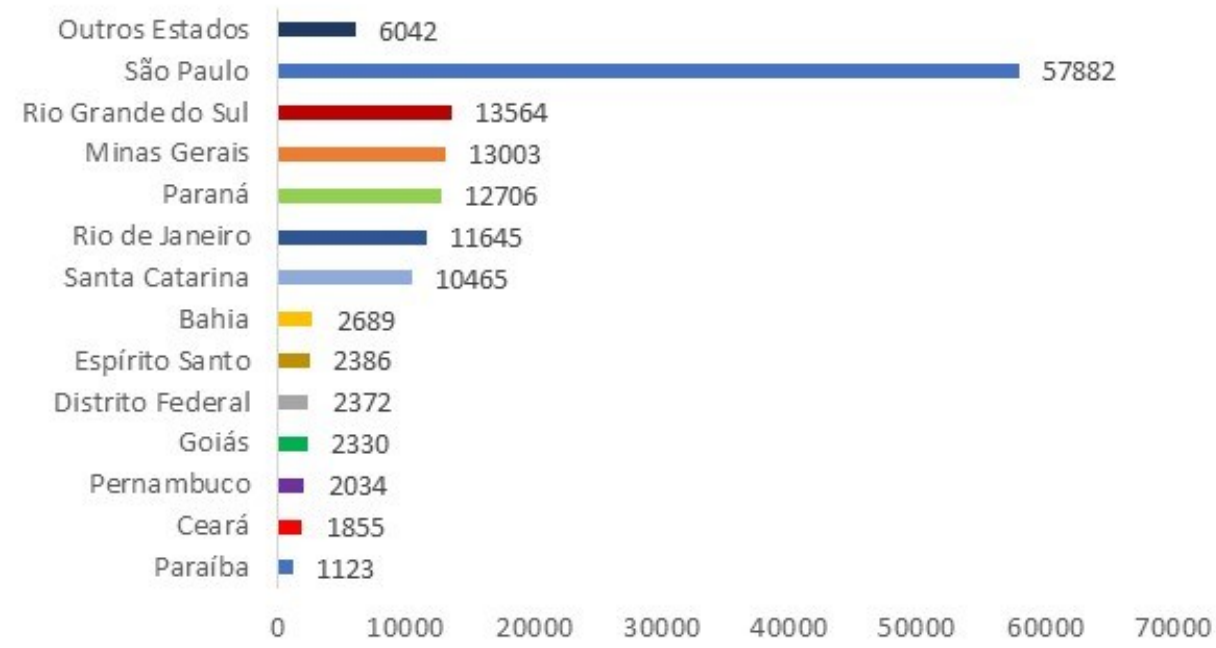

Fonte: Elaborado pelos autores (2020), com base nos dados do INPI.

Observa-se que por meio desse gráfico que Minas Gerais foi o terceiro Estado que mais depositou patentes junto ao INPI, perfazendo um total de 13.003 patentes depositadas, ficando atrás apenas de São Paulo e Rio Grande do Sul. Entretanto, cabe destacar que a Fundação de Amparo à Pesquisa do Estado de São Paulo - FAPESP - foi criada em 1960 e a Fundação de Amparo à Pesquisa do Estado do Rio Grande do Sul - FAPERGS foi instituída em 1964, ou seja, praticamente duas décadas antes do surgimento da FAPEMIG, o que nos leva a crer que as políticas públicas desenvolvidas no Estado de MG estão sendo efetivas e eficazes.

Aqui também se percebe uma grande discrepância em relação ao número de depósitos de patentes, visto que cerca de $85 \%$ dos depósitos são realizados por apenas seis Estados da Federação, pertencentes as regiões Sudeste e Sul, demonstrando, mais uma vez, a necessidade de criação de políticas públicas para atender às demais regiões.

Não obstante, para tornar o Brasil um país inovador, é necessário não somente desenvolver uma política consistente de investimento em $\mathrm{P} \& \mathrm{D}$, mas também em relação a proteção à propriedade intelectual, pois a patente nada mais é do que uma forma de proteger conhecimentos.

\section{CONCLUSÃO}

O presente trabalho se propôs apresentar uma análise das políticas públicas nacionais e de Minas Gerais voltadas para Ciência, Tecnologia e Inovação, bem como seus impactos na geração de patentes. A partir da análise realizada, foi possível observar que, embora o país tenha envidado esforços e ampliado o volume de recursos destinados ao tema, sua posição no ranking do Índice de Inovação Global necessita ser melhorada.

Os dados do MCTIC (2020) ratificam a ampliação nos recursos destinados à CT\&l no período, demonstrando a atenção do Governo Federal com o tema. Entretanto, se a análise for feita tendo como base o PIB, os dados mostram que a porcentagem dos dispêndios nacionais está aquém da meta prevista na Estratégia Nacional de Ciência e Tecnologia de se investirem 2\% do PIB em P\&D.

Os resultados demonstram que os dispêndios empresariais representam uma menor fatia dos investimentos realizados em CT\&l se comparados aos investimentos públicos realizados no Brasil, diferentemente de outros países, cuja participação empresarial atinge patamares muito mais significativos.

Constatou-se que há participação expressiva dos Estados na disponibilização de recursos públicos para CT\&l. Porém, restou evidente que tais investimentos não ocorrem de forma equânime, ficando concentrados nas regiões Sudeste e Sul, contribuindo para a manutenção das desigualdades regionais.

Particularmente em relação ao Estado de Minas Gerais, demonstrou-se que a inserção de uma política pública destinada a incentivar à inovação tecnológica no Estado e a participação mais efetiva da FAPEMIG no estabelecimento de planejamento para CT\&l de médio e longo prazo, trouxeram resultados relevantes ao Estado, visto que esse é o terceiro Estado do país com mais depósitos de patentes junto ao INPI, apesar de ser o sexto em valores gastos com P\&D. Esse fato pode ser associado a atuação da FAPEMIG e das Universidades Federais presente no Estado. 
Não obstante aos resultados encontrados, faz-se necessário que as políticas públicas, tanto nacionais quanto as do Estado de Minas Gerias sejam, de fato, cumpridas, a exemplo da destinação de percentuais definidos na Estratégia Nacional de Ciência e Tecnologia e na Constituição do Estado de Minas Gerais. Dessa forma, é possível melhorar a capacidade do país e do Estado de promoverem inovações, e, consequentemente, aumentarem a competitividade no que diz respeito ao depósito de patentes. Ademais, é importante que novas políticas sejam conduzidas no sentido de aumentar os investimentos privados em CT\&l

Em relação à contribuição teórica, este artigo amplia os estudos nacionais sobre a questão das políticas públicas voltadas para CT\&I no país e em Minas Gerais. Em termos práticos, pode contribuir com subsídios para a formulação de políticas públicas voltadas para a criação de incentivos que culminem em aumentos dos investimentos privados destinados à CT\&l, assim como políticas que combatem as assimetrias regionais, com objetivo de disseminar, de forma equânime, a participação de todos os Estados na produção de $P \& D$, bem como no depósito de patentes.

\section{REFERÊNCIAS}

ARBIX, G.; SALERNO, M. S.; AMARAL, G. L.; LINS, L. Avanços, equívocos e instabilidade das políticas de inovação no Brasil. Novos Estudos - CEBRAP, São Paulo, v. 36, n. 3, p. 9-27, nov. 2017.

BRASIL, F. G.; CAPELLA, A. C. N. Os Estudos das Políticas Públicas no Brasil: passado, presente e caminhos futuros da pesquisa sobre análise de políticas. Revista Política Hoje, [S.I.], v. 25, n.1, p. 71-90, 2016.

CERVO, A. L.; BERVIAN, P. A.; DA SILVA, R. Metodologia científica. 6. ed. São Paulo: Pearson Prentice Hall, 2007.

CGAI - DGI/SEXEC - MCTIC - Coordenação-Geral de Gestão Institucional - Departamento de Governança Institucional/ Secretaria Executiva - Ministério da Ciência, Tecnologia e Inovações. Indicadores Nacionais de Ciência, Tecnologia e Inovação. Várias Tabelas. 2019. Disponível em:

https://antigo.mctic.gov.br/mctic/export/sites/institucional/indicadores/arquivos/Indicadores_CTI_2019.pdf. Acesso em: 15 nov. 2020.

COTA, F. Governo de Minas abre consulta pública para atualização do Maro Legal Mineiro de Inovação. Agência RMBH. Belo Horizonte, out. 2020. Disponível em: http://www.agenciarmbh.mg.gov.br/governo-deminas-abre-consulta-publica-para-atualizacao-do-marco-legal-mineiro-de-inovacao/. Acesso em 20 mar. 2021.

DANTAS, S. C. S.; GOMES, I. S.; LOPES, L. M. C.; MEDEIROS, F. N.; OLIVEIRA, L. C. Proteção a propriedade industrial sobre a patente - Um desestímulo a inovação no país?. In: INTERNATIONAL SYMPOSIUM ON TECHNOLOGICAL INNOVATION (ISTI), 7., 2016, Aracaju. Anais [...]. Aracaju: ISTI, 2016. p. 252-258.

DEHNHARDT, M. R. A inovação tecnológica e os benefícios fiscais previstos na lei n 11.196/2005: desafios e possibilidades à gestão da inovação. 2013. 194 p. Dissertação (Mestrado Programa de PósGraduação em Gestão e Negócios) - Universidade do Vale do Rio dos Sinos, Porto Alegre, 2013.

DYE, T. D. Understanding Public Policy. Englewood Cliffs, N.J.: Prentice-Hall, 1984.

FARAH, M. F. S. Análise de políticas públicas no Brasil: de uma prática não nomeada à institucionalização do "campo de públicas". Revista de Administração Pública, São Paulo, v. 50, p. 959-979, nov./dez. 2016.

FAPEMIG - Fundação de Amparo à Pesquisa do Estado de Minas Gerais. FAPEMIG: menu-institucional quem somos. Belo Horizonte, MG. Disponível em: https://fapemig.br/pt/menu-institucional/quem-somos/. Acesso em 15 nov. 2020.

FAPEMIG - Fundação de Amparo à Pesquisa do Estado de Minas Gerais. FAPEMIG: uma década de conquistas: Relatório de gestão 2004-2014. Belo Horizonte, MG: FAPEMIG, 2014. Disponível em: https://fapemig.br/media/media/Relatorio_Gest\%C3\%A3o_MN_FINAL_oOSK2kn.pdf/. Acesso em 15 nov. 2020. 
GARCIA, F. P. Construção do novo "marco legal da ciência, tecnologia e inovação" do Brasil: um relato do esforço colegiado e transformador. In: NADER, H. B.; OLIVEIRA, F.; MOSSRI, B. B. (org.). A ciência e o poder legislativo: relatos e experiências. São Paulo: SBPC, 2017. p. 22-34.

HAIR JR, J. F.; BABIAN, B.; MONEY, A. H.; SAMOUEL, P. Fundamentos de métodos de pesquisa em administração. Porto Alegre: Bookman, 2005.

INPI - Instituto Nacional de Propriedade Intelectual. Indicadores de Propriedade Industrial. Instituto Nacional da Propriedade Industrial. Rio de Janeiro, RJ: INPI, 2020. Disponível em: https://www.gov.br/inpi/ptbr/central-de-conteudo/estatisticas. Acesso em: 18 nov. 2020.

INPI - Instituto Nacional de Propriedade Intelectual. Estatísticas Preliminares. Instituto Nacional da Propriedade Industrial. Rio de Janeiro, RJ: INPI, 2020. Disponível em: https://www.gov.br/inpi/pt-br/centralde-conteudo/estatisticas/estatisticas-preliminares-2013-a-partir-de-2013. Acesso em: 18 nov. 2020.

KOELLER, P.; VIOTTI, R. B.; RAUEN, A. Dispêndios do governo federal em C\&T e P\&D: esforços e perspectivas recentes. Radar IPEA, n. 48, p. 1-6, dez. 2016.

KORNIS, M. Conselho Nacional de Desnvolvimento Científico e Tecnológico. In: ABREU, A. A., et al. Dicionário Histórico-Biográfico Brasileiro - Pós 1930. Rio de Janeiro: CPDOC/FGV, 2010. Disponível em: http://www.fgv.br/cpdoc/acervo/dicionarios/verbete-tematico/conselho-nacional-de-desenvolvimentocientifico-e-tecnologico-cnpq. Acesso em 18 nov. 2020.

LASWELL, H.D. Politics: Who Gets What, When, How. Cleveland: Meridian Books, 1936.

LASWELL, H. D. The policy orientation. In: LERNER, Daniel; LASSWELL, Harold (Ed.). The policy sciences. Stanford: Stanford University Press, 1951. p. 102-120.

LYNN, L. E. Designing Public Policy: A Casebook on the Role of Policy Analysis. Santa Monica, Califórnia: Goodyear, 1980.

LOTTA, G. A política pública como ela é: contribuições dos estudos sobre implementação para a análise de políticas públicas. In: LOTTA, G. (org.). Teoria e análises sobre implementação de políticas públicas no Brasil. 1. ed. Brasília: ENAP, 2019, v. 1. p. 11-38.

MARÔCCO, A. P. A atuação da agência de fomento de Minas Gerais na implementação da política pública de Ciência, Tecnologia e Inovação. Dissertação (Programa de Pós-Graduação em Administração) Universidade Federal de Viçosa, Viçosa, MG, 2008.

MARQUES, F. Ciclo interrompido: indicadores de ciência e tecnologia do MCTIC mostram efeito da recessão nos dispêndios em pesquisa e desenvolvimento no país em 2016. Pesquisa FAPESP, São Paulo, p. 1-6, jan. 2019.

MARTELETO, R. M. A pesquisa em Ciência da Informação no Brasil: marcos institucionais, cenários e perspectivas. Perspectivas em Ciência da Informação, v. 14, número especial, p. 19-40, 2009.

MARTINS, G. A.; THEÓPHILO, C. R. Metodologiada investigação científica para ciências sociais aplicadas. 2. ed. São Paulo: Atlas, 2009.

MCTIC - Ministério da Ciência, Tecnologia e Inovações. Patentes. INPI - Escritório Brasileiro. Indicadores CT\&l. 2000-2020. Disponível em:

http://antigo.mctic.gov.br/mctic/opencms/indicadores/detalhe/Patentes/INPI/6.1.2.html Acesso em 15 nov. 2020.

MCTIC - Ministério da Ciência, Tecnologia e Inovações. Recursos Aplicados. Indicadores CT\&I. 2000-2018. Várias Tabelas. 2019. Disponível em:

http://antigo.mctic.gov.br/mctic/opencms/indicadores/detalhe/recursos_aplicados/RecursosAplicadosCeT.html Acesso em: 15 nov. 2020. 
OCDE. Manual de Oslo: diretrizes para a coleta e interpretação de dados sobre inovação tecnológica. 3. ed. BRASÍLIA: FINEP, 2006. Disponível em: https://www.finep.gov.br/images/apoio-efinanciamento/manualoslo.pdf. Acesso em: 06 jul. 2021.

OLLAIK, L.; MEDEIROS, J. J. Instrumentos governamentais: reflexões para uma agenda de pesquisas sobre implementação de políticas públicas no Brasil. Revista de Administração Pública, Rio de Janeiro, v. 45, p. 1943-1967, nov./dez. 2011.

PETERS, B. G. American Public Policy. Chatham, N.J.: Chatham House, 1986.

PRETE, E. K. E. Considerações para uma abordagem sistemática da Emenda Constitucional 85 de 2015. In: SOARES, F. M.; PRETE, E. K. E. (org.). Marco regulatório em ciência, tecnologia e inovação: texto e contexto da Lei no 13.243/2016. Belo Horizonte: Arraes Editores, 2018. p. 93-115.

RAUEN, C. V. O Novo Marco Legal da Inovação no Brasil: o que muda na Relação ICT-Empresa? Radar IPEA, v. 43, p. 21-35, fev. 2016.

REZENDE, A. A.; CORRÊA, C. R.; DANIEL, L. P. Os impactos da política de inovação tecnológica nas universidades federais: uma análise das instituições mineiras. Revista de Economia e Administração, v. 12, n. 1, p. 100-131, jan./mar. 2013.

SALERNO, M. S.; KUBOTA, L. C. Estado e Inovação. In: NEGRI, J. A. D.; KUBOTA, L. C. (org.). Políticas de Inventivo à Inovação Tecnológica no Brasil. Brasília: IPEA, 2008. p. 13-64.

SCHWARTZMAN, S. Modos de produção do conhecimento científico e tecnológico e as oportunidades para o setor de ensino superior particular: apresentação em evento. In: VI ENCONTRO NACIONAL DE PÓSGRADUAÇÃO NAS IES PARTICULARES, 6., 2005, Salvador. Anais [...]. Salvador: [s.n.], 2005. p. 1-13.

SCHUMPETER, J. A. Capitalism, socialism and democracy. New York: Harper and Brothers, 1961.

SOUZA, C. Políticas Públicas: uma revisão da literatura. Sociologias, Porto Alegre, v. 20, ano 8, n. 16, p. 20-45, jul./dez. 2006.

TOLEDO, P. T. M. A gestão estratégica de Núcleos de Inovação: cenários, desafios e perspectivas. In: SANTOS, M. E. R. D.; TOLEDO, P. T. M. D.; ROBERTO. (org.). Transferência de Tecnologia: estratégias para a estruturação e gestão de Núcleos de Inovação Tecnológica. Campinas: Komedi, 2009. p. 109-166.

UNESP. Tipos de revisão de literatura. Botucatu: UNESP, 2015. Disponível em: https://www.fca.unesp.br/Home/Biblioteca/tipos-de-evisao-de-literatura.pdf. Acesso em: 06 jul. 2021.

UNIVERSIDADE CORNELL, INSEAD e OMPI. Índice Global de Inovação 2020: Quem financiará a inovação? [2020]. Disponível em: https://www.wipo.int/edocs/pubdocs/pt/wipo_pub_gii_2020.pdf. Acesso em: 15 nov. 2020. 